\title{
TU/e emonownen

\section{The influence of thermodynamic activity on the solute rejection in multicomponent systems}

Citation for published version (APA):

Oers, van, C. W., Vorstman, M. A. G., Hout, van den, R., \& Kerkhof, P. J. A. M. (1997). The influence of thermodynamic activity on the solute rejection in multicomponent systems. Journal of Membrane Science, 136(1-2), 71-87. https://doi.org/10.1016/S0376-7388(97)00153-1

DOI:

10.1016/S0376-7388(97)00153-1

Document status and date:

Published: 01/01/1997

\section{Document Version:}

Publisher's PDF, also known as Version of Record (includes final page, issue and volume numbers)

\section{Please check the document version of this publication:}

- A submitted manuscript is the version of the article upon submission and before peer-review. There can be important differences between the submitted version and the official published version of record. People interested in the research are advised to contact the author for the final version of the publication, or visit the $\mathrm{DOI}$ to the publisher's website.

- The final author version and the galley proof are versions of the publication after peer review.

- The final published version features the final layout of the paper including the volume, issue and page numbers.

Link to publication

\section{General rights}

Copyright and moral rights for the publications made accessible in the public portal are retained by the authors and/or other copyright owners and it is a condition of accessing publications that users recognise and abide by the legal requirements associated with these rights.

- Users may download and print one copy of any publication from the public portal for the purpose of private study or research.

- You may not further distribute the material or use it for any profit-making activity or commercial gain

- You may freely distribute the URL identifying the publication in the public portal.

If the publication is distributed under the terms of Article 25fa of the Dutch Copyright Act, indicated by the "Taverne" license above, please follow below link for the End User Agreement:

www.tue.nl/taverne

Take down policy

If you believe that this document breaches copyright please contact us at:

openaccess@tue.nl

providing details and we will investigate your claim. 


\title{
The influence of thermodynamic activity on the solute rejection in multicomponent systems
}

\author{
C.W. van Oers ${ }^{1, *}$, M.A.G. Vorstman, R. v.d. Hout, P.J.A.M. Kerkhof \\ Department of Chemical Process Technology, Eindhoven University of Technology, P.O. Box 513, 5600 MB Eindhoven, The Netherlands
}

Received 27 January 1997; received in revised form 12 June 1997; accepted 12 June 1997

\begin{abstract}
In this study it has been shown that major changes in solute rejection can occur when the solute is part of a multicomponent system instead of a binary system. The effect of changes in the thermodynamic activity of the solute on its rejection has been studied.

As a model system the combined ultrafiltration of poly(ethylene glycol) (PEG) and dextran has been chosen. The thermodynamic activities of PEG and dextran have been modelled with the UNIQUAC model.

Rejection measurements showed a decrease in the observed PEG rejection when dextran was added to the solutions under conditions where the dextran was mainly retained by the membrane. At high dextran concentrations and low fluxes the PEG rejection even became strongly negative. The PEG concentration in the permeate was at maximum a factor 2 higher than in the permeate (on a dextran-free basis). For a more open membrane the rejection of PEG was found to increase in the presence of dextran.

The elevated transport of PEG through the membrane in the presence of dextran was ascribed to the additional driving force due to the increased thermodynamic activity of PEG at the retentate side of the membrane.

The results in this paper show that thermodynamic interactions can have a strong impact on the observed rejection and are certainly worth being considered in multicomponent systems.
\end{abstract}

Keywords: Thermodynamics; Rejection; Multicomponent; Ultrafiltration

\section{Introduction}

Ultrafiltration is a technique which finds an increasingly wider application in industrial processes. Considerable research effort has been performed to describe the solute transport during ultrafiltration. However, this research mainly focused on the trans-

\footnotetext{
*Corresponding author. Fax: +31263665108.

${ }^{1}$ Present address: Akzo Nobel Central Research, RTA, P.O. Box 9300, 6800 SB Arnhem, The Netherlands.
}

port of a single solute through a membrane. In industrial applications the solutions to be filtered are often a complex mixture of various components. The interaction of different solute molecules can strongly influence the rejection of a single component.

Although Strathmann [1] already mentioned in 1973 the possible increase in rejection of other components in the presence of a deposit of a fully rejected component, relatively few data are available on the solute rejection in multicomponent systems. Nakao [2] and Kimura [3] both observed an increase in low 
molecular weight solute rejection by ovalbumin and poly(vinyl alcohol) layers during ultrafiltration. During the filtration of enzymes Kerkhof [4] observed an increase in rejection of a colour component with pressure, which was ascribed to the formation of a secondary membrane. In two recent studies Mochizuki separately investigated the effect of BSA adsorption [5] and BSA deposition [6] on the rejection of a polydisperse mixture of dextrans for open microfiltration membranes. The adsorption of BSA occurred preferentially in the largest pores causing a rise in dextran rejection compared to that of the clean membrane. The protein deposit also increased dextran rejection depending on solution $\mathrm{pH}$, ionic strength, and salt composition. Meireles [7] studied the effect of protein fouling on the rejection characteristics of low molecular weight cut-off ultrafiltration membranes. For $10 \mathrm{kDa}$ membranes the dextran rejection coefficients were not affected, but a significant increase in rejection was found for $40 \mathrm{kDa}$ membranes. The influence of the presence of open and compact deposit layers on the rejection of other solutes has been discussed by van Oers [8]. It was shown that compact deposit layers caused an increase in rejection, whereas open deposit layers led to a decrease of the rejection to almost zero.

Besides adsorption and gel layer formation, other effects can influence the rejection in a multicomponent system. Papamichael and Kula [9] observed for the combined filtration of PEG and BSA, besides an increase in PEG rejection, a decrease in PEG rejection compared to the rejection on a clean membrane. They suggest that this might be explained by the interaction of PEG and BSA. According to Busby [10] proteinprotein interactions can interfere with the attempts to separate proteins by ultrafiltration. Tam [11] has shown that solute-solute interference in the solution can also occur using data for the rejection characteristics for a five-component mixture of poly(ethylene glycol)s versus that for a single component solution. The higher rejection of a component in the mixture was ascribed to the hindered movement of the smaller solutes caused by the presence of the larger solutes. Bozzano [12] found that the permeation of proteins was lowered in the presence of poly(acrylic acid) due to a complexation reaction.

Finally, charge effects can also play a role in ultrafiltration. Wesselingh and Vonk have shown that negative $\mathrm{NaCl}$ rejections can occur in the presence of BSA [13] due to Donnan exclusion, similar to the observed effects during nanofiltration [14].

To obtain a better understanding of the interaction of solutes the mutual influence of the components on their rejections has been investigated for several model systems [15]. In this paper we will focus on a model system with uncharged components, in which no deposit layer is formed on the membrane surface. Starting from the Stefan-Maxwell description of transport it will be shown that even without the presence of a deposit layer on the membrane surface, the addition of another component can be affected by changes in the gradient of the chemical potential as a result of different thermodynamic behaviour due to the presence of another component. Besides the thermodynamic behaviour the friction between the components can also result in a change in rejection. The possible influence of these phenomena has been studied for combinations of poly(ethylene glycol) (PEG)/dextran/water as a model system. Both PEG and dextran form only a polarization layer on the membrane; no deposit layer is formed under the experimental conditions used $[15,16]$. Especially in the case of dextran the extent of the concentration polarization can be considerable. Since the PEG/dextran/water system shows demixing into two liquid phases the solutes mutually influence their thermodynamic activities to a considerable extent [17].

In order to be able to interpret the flux and rejection in the ternary system the thermodynamic behaviour has been modelled by UNIQUAC and the Linearized Quasi-Chemical Approach (LQCA). In the experimental part the permeate flux for the ternary system will be discussed first. Subsequently, the rejection in the ternary system will be evaluated and compared with the PEG and dextran rejection in the binary systems. An explanation in terms of changes in the values of the activity coefficients will be presented.

\section{Theory}

\subsection{Transport model}

For the present study it is imperative to use a description of the mass transport in which the driving 
force for mass transport is not the gradient of the concentration or the mole fraction of a component, but the gradient of the chemical potential of the components. The generalized Stefan-Maxwell equations fulfil this requirement. In these equations transport is described in terms of intermolecular friction. The driving force exerted on a species is counteracted by the friction with all the other species present in the system. The friction between two species is assumed to be proportional to their relative amounts and to the differences in velocities.

During ultrafiltration a polarization layer can occur in front of the membrane. In case electrical effects can be neglected the Stefan-Maxwell equation for the polarisation layer reads:

$\frac{x_{j}}{R T} \nabla_{\mathrm{T}, \mathrm{P}} \mu_{j}=\sum_{\substack{k=1 \\ k \neq j}}^{n_{\mathrm{conp}}} \frac{x_{j} N_{k}-x_{k} N_{j}}{c_{\mathrm{t}} D_{j, k}^{\mathrm{sm}}}$

It is assumed that interactions only occur in the solution itself; no interactions with the membrane surface are taken into account for the polarization layer. In our case we assume that the solution remains fluid throughout the polarization layer so that $\nabla P$ is equal to zero and therefore not incorporated in Eq. (1). If, however, one of the species forms a gel or precipitate adjacent to the membrane, a force is transmitted from the membrane to this species and a hydrodynamic pressure gradient will develop within the concentrated layer [18].

Several authors have applied the Stefan-Maxwell equations to transport in membranes or in porous media [18-24]. Some consider the membrane as a homogeneous phase, others see the membrane as a porous, heterogeneous phase. Van Oers [15] has made a detailed derivation of both the homogeneous and the heterogeneous description, since inconsistencies seem to occur in the texts as the result of the unclear definitions of the concentrations, fluxes and velocities. Some authors add a viscous term to the equations, others do not. It is the aim of this paper, however, to focus on what these models have in common, rather than to comment on the differences.

For a system in which no body forces are present Lightfoot [18], for instance, describes the transport in a membrane by:

$$
\begin{aligned}
\frac{x_{j}^{\prime \prime}}{R T} & \nabla_{\mathrm{T}, \mathrm{P}} \mu_{j}+\frac{x_{j}{ }^{\prime \prime} V_{j}}{R T} \nabla P \\
& =\sum_{\substack{k=1 \\
k \neq j}}^{n_{\text {comp }}} \frac{x_{j}^{\prime \prime} N_{k}-x_{k}{ }^{\prime \prime} N_{j}}{c_{\mathrm{t}}{ }^{\prime \prime} D_{j, k}^{\mathrm{sm}} \frac{\varepsilon}{\tau}}-\frac{N}{c_{\mathrm{t}}{ }^{\prime \prime} D_{j, m} \frac{\varepsilon}{\tau}}
\end{aligned}
$$

in which the superscript " is added to stress that mole fractions and concentrations are local values (averaged over the pore cross-section) based on the liquid phase inside the pores, thus based on the open volume fraction $\varepsilon$ of the membrane and the flux $N$ is based on the total membrane area, as it is in Eq. (1).

The mole fraction of partly rejected solutes inside the membrane pores is lower than in the free solution at the membrane interface due to steric exclusion by a factor $K$, the steric exclusion coefficient. According to Ferry [25]:

$$
K=\left(1-\frac{d_{\text {solute }}}{d_{\text {pore }}}\right)^{2}
$$

in which $d_{\text {solute }}$ and $d_{\text {pore }}$ are the diameters of the solute and the pore. The addition of a second solute may change the distribution coefficient significantly due to differences in the activity coefficient. If equilibrium is assumed at the interfaces between membrane and retentate or permeate the following equilibrium relation will hold for all components that are able to enter the pores [18]:

$R T \ln \left(\gamma_{j} x_{j}\right)+V_{j} P=R T \ln \left(\gamma_{j}^{\prime \prime} x_{j}^{\prime \prime}\right)+V_{j} P^{\prime \prime}$

or:

$\frac{x_{j}^{\prime \prime}}{x_{j}}=K=\frac{\gamma_{j}}{\gamma_{j}^{\prime \prime}} \exp \left(V_{j}\left(P-P^{\prime \prime}\right)\right)$

If the activity of Solute (1) is increased by the addition of Solute (2) and this solute is retained much stronger than Solute (1), an additional driving force for Solute (1) is created over the membrane. This is the result of the fact that the activity coefficient of Solute (1) in front of the membrane will be more augmented than in the permeate. Consequently, the distribution coefficient at the retentate side of the membrane will be larger than at the permeate side.

The above-mentioned models, basically Eqs. (1)(4) or their equivalents from the various authors, have been applied to describe protein transport [23], ultra- 
filtration of a PEG/water system [15,24] and of a $\mathrm{PEG} /$ potassium phosphate/water system [26]. In order to carry out calculations with the model the values of a large number of physical parameters, among which the binary diffusivities between all components, has to be known. Membrane parameters like pore size and a value for $\varepsilon / \tau$ and the size exclusion coefficient and membrane diffusion coefficients have to be fitted for each component.

In case all physical parameters are not known and a quantitative calculation is impossible, the form of Eqs. (1) and (2) is not very suited for qualitative reasoning. For that purpose Eq. (1) and the various versions of Eq. (2) are better rewritten into an explicit relation for the flux of the solute, $N_{\mathrm{s}}$, as was done before by several authors [18,23,27]. The only difference with these relations is that we use the total gradient of the chemical potential as the driving force for diffusion:

$\nabla_{T} \mu_{j}=R T \nabla \ln a_{j}+V_{j} \nabla P$

instead of only relating it to the activity gradient of the solute.

A few expressions for the flux will be given below for comparison to illustrate the similarity among the various versions of the transport model, both for the polarization layer and in the membrane. To keep the relations simple we restrict ourselves to binary systems in which the solvent will be denoted by the subscript w (water). We will not present the relations for the total flux since we plan to compare the experimental results for different bulk compositions at the same total flux.

Solving $N_{\mathrm{s}}$ from Eq. (1) by taking into account that $N_{\mathrm{w}}=N_{\mathrm{t}}-N_{\mathrm{s}}$ gives:

$N_{\mathrm{s}}=N_{\mathrm{t}} x_{\mathrm{s}}-C_{\mathrm{t}} D_{\mathrm{sw}} x_{\mathrm{s}} \nabla_{\mathrm{T}, \mathrm{P}} \ln a_{\mathrm{s}}$

Apart from the driving force, Eq. (6) is equivalent to Fick's law. For a constant total concentration this equation reduces to the well-known equation from the polarization model [28], again with a different driving force:

$N_{\mathrm{s}}=v_{\mathrm{t}_{\mathrm{t}}} x_{\mathrm{s}}-C_{\mathrm{t}} D_{\mathrm{sw}} x_{\mathrm{s}} \nabla_{\mathrm{T}, \mathrm{p}} \ln a_{\mathrm{s}}=v_{\mathrm{p}} C_{\mathrm{s}, \mathrm{p}}$

If the hydrodynamics of the cross flow over the membrane is laminar, analytical or numerical solutions can be developed, and for turbulent flow more sophisticated models may also be applied $[24,29,30]$.

The right hand side of both Eqs. (6) and (7) is composed of a diffusive and convective part. Zydney [31] introduced a frictional hindrance factor in the convective part of the equation to account for the concentration dependence of the diffusivity.

For the transport in the membrane Eq. (2) reduces for a single solute system into:

$$
\begin{aligned}
N_{\mathrm{s}}= & \frac{1}{1+D_{\mathrm{sw}} / D_{\mathrm{sm}}} N_{\mathrm{t}} x_{\mathrm{s}}-\frac{C_{\mathrm{t}} \frac{\varepsilon}{\tau} D_{\mathrm{sw}}}{1+D_{\mathrm{sw}} / D_{\mathrm{sm}}} \\
& \times\left(x_{\mathrm{s}} \nabla_{\mathrm{T}, \mathrm{P}} \ln a_{\mathrm{s}}+\frac{x_{\mathrm{s}} V_{\mathrm{s}}}{R T} \nabla P\right)
\end{aligned}
$$

Robertson [23] derived an equation for the limiting case of a dilute solution form, in which case $N_{\mathrm{t}}$ can be replaced by $c_{\mathrm{t}} * v$. The dilute solution limit of Eq. (8) reads:

$$
\begin{aligned}
N_{\mathrm{s}}= & \frac{1}{1+D_{\mathrm{sw}} / D_{\mathrm{sm}}} C_{\mathrm{t}} \nu x_{\mathrm{s}}-\frac{C_{\mathrm{t}} \frac{\varepsilon}{\tau} D_{\mathrm{sw}}}{1+D_{\mathrm{sw}} / D_{\mathrm{sm}}} \\
& \times\left(x_{\mathrm{s}} \nabla_{\mathrm{T}, \mathrm{P}} \ln a_{\mathrm{s}}+\frac{x_{\mathrm{s}} V_{\mathrm{s}}}{R T} \nabla P\right)
\end{aligned}
$$

Eq. (9) differs from the equation given by Robertson, since the driving force is taken differently. According to the hydrodynamic model $[32,33]$ the transport in the membrane is described by:

$N_{\mathrm{s}}^{\prime \prime}=K_{\mathrm{c}} v^{\prime \prime} C_{\mathrm{s}}^{\prime \prime}-K_{\mathrm{d}} D_{\mathrm{sw}} \frac{\mathrm{d} C_{\mathrm{s}}^{\prime \prime}}{\mathrm{d} z}$

We would replace the driving force in Eq. (10) by the gradient of the chemical potential.

Eqs. (8)-(10) are composed of two terms which could, like in the polarization layer, be denoted as a convective and a diffusive term. The only difference between the equations is the type of coefficients by which these terms are expressed. The analogous expressions for the solute flux in single solute systems of Mason [27] and of Kerkhof [24] are also of the same form but with different parameters in the coefficients for the convective and diffusive contributions. It was shown that the parameters from the various models can be translated in each other [15,27].

To summarize: all above-mentioned relations have in common that the solute flux can mathematically be attributed to two differently weighed terms: a con- 
vective and a diffusive transport term, of which the latter is governed by the gradient of the chemical potential. This concept of the transport in the polarization layer and in the membrane may be used in a qualitative interpretation of filtration data in which a strong variation of activity coefficients occurs.

The chemical potential gradient is the driving force for the diffusive part of the transport as can be seen from Eqs. (6)-(10). In the case the diffusive transport is in the same order of magnitude as the convective transport caused by the pressure gradient, the mutual thermodynamic interaction between the components can play a significant role in the transport and therefore the rejection of the components. Changes in the activity due to interaction of added components will also lead to a change in the equilibrium at the solution/membrane interface (Eq. (4)), thus giving rise to a possible change in rejection. A change in rejection can even be observed if the diffusive flux is of minor importance. Depending on the circumstances both a decrease and increase in rejection can be observed compared to the binary system, as will be confirmed by experiments and discussed in Section 4 .

\subsection{Thermodynamic activity of components in polymer solutions}

To be able to describe the thermodynamic behaviour in multicomponent solutions the UNIQUAC model, derived by Abrams and Prausnitz [34] was used. This model has been applied by Kang and Sandler [17] to predict demixing curves for PEG/dextran/water systems. Our interest is not to predict the demixing curve, instead, it is to describe the thermodynamic activity of the components in the homogeneous solution. The model presented here is a simplified model which does not take the molecular weight distribution of the polymers into account. (For the extended model with molecular weight distribution, see Kang and Sandler [35].) First, a general description of the model is given. Subsequently, the model is applied to the PEG/dextran/water system.

The UNIQUAC model is composed of two parts: a combinatorial contribution and a part which describes the intermolecular forces responsible for the Gibbs free energy of mixing.

The activity of component $j$ in an $n$ component system can be represented in terms of the mass frac- tions by the following relationship [17]:

$$
\begin{aligned}
\ln a_{j}= & \ln \phi_{j}{ }^{\prime}+\frac{z}{2} M_{j} q_{j} \ln \frac{\theta_{j}{ }^{\prime}}{\phi_{j}{ }^{\prime}}+M_{j} l_{j}{ }^{\prime}-M_{j} \frac{\phi_{j}{ }^{\prime}}{w_{j}} \sum_{k=1}^{n} l_{k}{ }^{\prime} w_{k} \\
& +M_{j} q_{j}^{\prime}\left(1-\ln \sum_{k=1}^{n} \theta_{k}{ }^{\prime} \tau_{k j}-\sum_{k=1}^{n} \frac{\theta_{k}{ }^{\prime} \tau_{j k}}{\sum_{m=1}^{n} \theta_{m} \tau_{m k}}\right)
\end{aligned}
$$

in which the various quantities are defined as follows:

$$
\begin{aligned}
\phi_{j}^{\prime} & =\frac{r_{j}^{\prime} w_{j}}{\sum_{k=1}^{n} r_{k} w_{k}} \quad \theta_{j}^{\prime}=\frac{q_{j}^{\prime} w_{j}}{\sum_{k=1}^{n} q_{k} w_{k}} \\
l_{j}^{\prime} & =\frac{z}{2}\left(r_{j}^{\prime}-q_{j}^{\prime}\right)-\left(r_{j}^{\prime}-\frac{1}{M_{j}}\right) \\
\tau_{j k} & =\exp \left(\frac{-A_{j k}}{T}\right) \quad A_{j k}=\frac{\left(u_{j k}-u_{j j}\right)}{R}
\end{aligned}
$$

The parameters $r_{j}^{\prime}$ and $q_{j}^{\prime}$ for the various components can be calculated as shown by Fredenslund et al. [36].

The activity coefficients may be evaluated based on the mass fractions: $\gamma_{j}^{\mathrm{wt}}=a_{j} / w_{j}\left[\mathrm{~kg} \mathrm{~kg}^{-1}\right]$ or on the mole fractions: $\gamma_{j}=a_{j} / x_{j} \quad\left[\mathrm{~mol} \mathrm{~mol}^{-1}\right]$. The last expression is used in the Stefan-Maxwell equations. The activity coefficients presented in the graphs in this paper are all based on mass fractions.

For the activity coefficients the following conventions will be used (for a ternary system):

$$
\begin{array}{ll}
\text { polymer : } & \gamma_{1}^{\mathrm{wt}}=1 \text { for } w_{1} \rightarrow 0 \\
& \gamma_{2}^{\mathrm{wt}}=1 \text { for } w_{2} \rightarrow 0 \\
\text { solvent }: & \gamma_{3}^{\mathrm{wt}}=1 \text { for } w_{3} \rightarrow 0
\end{array}
$$

This requires that the activity for the polymers calculated by Eq. (11) is corrected for the activity coefficient found at infinite dilution.

\subsubsection{Thermodynamic activities in a PEG/dextran/water system}

The thermodynamic activities in a PEG/dextran/ water system have been modelled with the UNIQUAC model. In Table 1 the values for the volume parameters $r_{j}^{\prime}$ and the surface area parameters $q_{j}^{\prime}$ for PEG, dextran and water are given as provided by Kang and Sandler [17].

For the ternary PEG/dextran/water system six interaction parameters should be fitted to the experimental data. The polymer-water interaction parameters are determined from osmotic pressure data 
Table 1

Volume and surface area parameters

\begin{tabular}{llll}
\hline Parameter & $\begin{array}{l}\text { PEG1000 } \\
\text { PEG3400 }\end{array}$ & DextranT70 & Water \\
& 0.0387 & 0.02717 & 0.0511 \\
\hline$r_{j}^{\prime}\left[\mathrm{mol} \mathrm{g}^{-1}\right]$ & 0.0257 & 0.0196 & 0.0778 \\
$q_{j}^{\prime}\left[\mathrm{mol} \mathrm{g}^{-1}\right]$ & & \\
\hline
\end{tabular}

for the binary systems. The osmotic pressure is equal to

$\Pi=-\frac{R T}{V_{\mathrm{w}}} \ln \left(a_{\mathrm{w}}\right)$

By adjusting the polymer-water interaction parameters $A_{j 3}$ and $A_{3 j}$, the water activity according to the UNIQUAC model can be fitted to the water activity derived from experimental osmotic pressure data for binary systems using Eq. (16). Van der Linden [37] has measured the osmotic pressure for several types of PEG by determining the vapour pressure for various concentrations. The following relationships correspond to the curves drawn through the data points [37]:

$$
\begin{aligned}
\text { PEG1000: } \quad \Pi= & \frac{R T M_{\text {water }}}{1000 \mathrm{~V}_{\text {water }}} m_{\mathrm{PEG}}(0.970 \\
& \left.+3.183 m_{\mathrm{PEG}}+2.09 m_{\mathrm{PEG}}^{2}\right) \\
\text { PEG3400: } \quad \Pi= & \frac{R T M_{\text {water }}}{1000 \mathrm{~V}_{\text {water }}} m_{\mathrm{PEG}}(0.940 \\
& \left.+0.0126 C_{\mathrm{PEG}}\right)
\end{aligned}
$$

The molality $m_{\mathrm{PEG}}$ is expressed in $[\mathrm{mol}(\mathrm{kg}$ solvent $)^{-1}$ ]. Eq. (17) is valid for $C_{\mathrm{PEG}}<100 \mathrm{~kg} \mathrm{~m}^{-3}$ and Eq. (18) for $C_{\mathrm{PEG}}<70 \mathrm{~kg} \mathrm{~m}^{-3}$. The osmotic pressure of PEG1000 is higher than that for PEG3400 at a given mass fraction.

The osmotic pressure for dextran T70 has been measured by Wijmans et al. [28]:

$\Pi=37.5 C+0.752 C^{2}+76.4 \times 10^{-4} C^{3}$

This relationship is valid for $C_{\mathrm{dex}}<260 \mathrm{~kg} \mathrm{~m}^{-3}$ at $298 \mathrm{~K}$.

As a first approach it is assumed that the fitted polymer-water interaction parameters are also valid for concentrations higher than those for which osmotic pressure data are available. This assumption is necessary to be able to calculate the activities for the highly concentrated demixing phases.
For two phases in equilibrium, the chemical potentials of each component are equal in both phases: $\mu_{j}^{\mathrm{I}}=\mu_{j}^{\mathrm{II}}$. If for several mixtures the mass fractions of the components of two coexisting phases are known, the polymer-polymer interaction parameters $A_{12}$ and $A_{21}$ can be determined using this condition. The polymer-water interaction parameters derived from binary data are assumed to be valid in the ternary system.

The polymer-polymer interaction parameters have been fitted to experimental demixing data from the literature for the PEG3400/dextranT70/water system [38]. Since the interaction parameters in the UNIQUAC model are based on a unit area of interacting surface, these parameters should apply for all poly(ethylene glycol)s and dextrans, independent of the molecular weight, provided that the molecules are linear and their conformations are equal to those for the PEG3400/dextranT70/water system. According to Kang and Sandler [17], low molecular weight PEG molecules $\left(M_{\mathrm{n}}<1.0 \times 10^{4}\right)$ are likely to be similar in structure. Although dextran is not stretched out in solution but behaves almost like an ideal coil, it may suffice that dextran has the same conformation in both systems. In that case the statistical weights of contact sites along the chain may be similar. Based on these assumptions the polymer-polymer interaction parameters for PEG1000 and dextranT70 have been taken to be equal to the interaction parameters for PEG3400 and dextranT70, since no experimental demixing data are available for the PEG1000/dextranT70/water system.

In Table 2 the fitted interaction parameters are given for PEG1000, PEG3400, dextranT70 and water. Their values will be discussed later. The experimental and fitted osmotic pressures of PEG3400 and dextranT70 are depicted in Fig. 1(a) and (b), respectively.

Table 2

Interaction parameters $A_{j k}[\mathrm{~K}]$ for the UNIQUAC model

\begin{tabular}{lllll}
\hline & \multicolumn{3}{l}{ Component $k$} \\
\cline { 2 - 5 } Component $j$ & PEG1000 & PEG3400 & DextranT70 & Water \\
\hline PEG1000 & 0 & - & -8.18 & -308.9 \\
PEG3400 & - & 0 & -8.18 & -261.4 \\
DextranT70 & 123 & 123 & 0 & -215.3 \\
Water & 139.7 & -105.6 & 13.06 & 0 \\
\hline
\end{tabular}


(a)

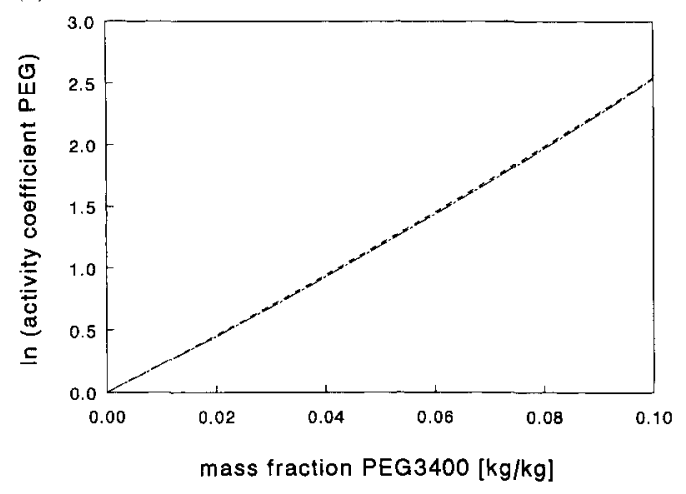

(b)

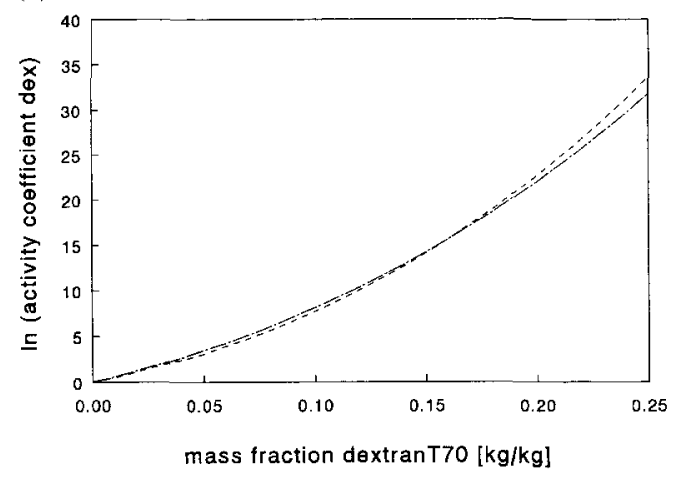

Fig. 1. (a) Comparison between the experimental osmotic pressure data for PEG3400 ( $\square$ ) and the model fit according to UNIQUAC (-.) and LQCA (- - ). (b) Idem for dextranT70.

Fig. 1(a) and (b) shows that the description of the UNIQUAC model for PEG3400 is excellent, while the osmotic pressure of dextranT70 is somewhat underestimated at the highest mass fractions.

The interaction parameters $A_{\text {water,PEg for PEG1000 }}$ and PEG3400 in Table 2 seem inconsistent. Their sign is opposite, whereas these interaction parameters are expected to be equal according to the same considerations as presented above for the polymer-polymer interaction parameters. This is the result of a strong correlation between the parameters $A_{j k}$ and $A_{k j}$. A range of combinations between these parameters for every set of components results in almost identical values for the activities of the three components. Illustrative in this respect is the fact that although the water-polymer interaction parameters for PEG3400 and PEG1000 are totally different, the osmotic pressure of PEG1000 can be predicted very well by means of the polymer-water interaction parameters of PEG3400.

The UNIQUAC model which is based on a lattice model, assumes that six interaction parameters are necessary to describe a ternary system. In cases in which only interaction energies between nearest neighbours are relevant and no steric interactions take place, no more than three independent interaction parameters can be defined in a lattice model for a ternary system [39]. Kang and Sandler [40] indeed reported a strong correlation between the polymerpolymer interaction parameters $A_{j k}$ and $A_{k j}$. According to our calculations for the UNIQUAC model, the polymer-water interaction parameters $A_{j k}$ and $A_{k j}$ are also correlated. Therefore, an alternative model is considered which assumes that the interaction between each pair of components can be described by one interaction parameter instead of two. This model, the Linearized Quasi-Chemical Approximation (LQCA), consists of three parts [41]. The first part represents the combinatorial contribution. The second part is an entropic nearest segment connectivity correction. This statistical correction accounts for the fact that polymer segments are connected to each other and cannot be located independently of each other on an arbitrary site in the solution. The last part describes the intermolecular forces which are responsible for the mixing enthalpy.

Comparison between the results obtained with both models shows that they both fit a similar relationship between the osmotic pressure and the mass fraction. According to Fig. 1(a) no difference in osmotic pressure for both models is found for PEG3400. Fig. 1(b) illustrates that at low mass fractions the osmotic pressure of dextran according to the LQCA model is slightly lower than that for the UNIQUAC model; at higher mass fractions the situation is reversed.

Our main interest is the activities of the polymers in the solution. The activity coefficients have been calculated relative to the values for the natural logarithm of the activity coefficients at infinite dilution: -966.68 for dextranT70 and $\mathbf{- 9 3 . 7 3}$ for PEG3400. In the relevant concentration ranges $\ln \left(\gamma_{\mathrm{PEG}}^{\mathrm{wt}}\right)$ is a linear function of the mass fraction, whereas $\ln \left(\gamma_{\text {dex }}^{\mathrm{wt}}\right)$ shows a more than linear increase with mass fraction (see Fig. 4(a) and (b)). The mutual influence of PEG and dextran on the activity coefficients will be discussed in Section 4 . The differences between the two models 
lead to a maximum difference of about $5 \%$ in the $\ln \gamma$ for dextranT70 at a mass fraction of 0.25 . The description of the PEG activity is equivalent for both models.

We have chosen the UNIQUAC model for the calculation of the thermodynamic behaviour in this paper.

\section{Experimental}

\subsection{Model components}

Use was made of two types of poly(ethylene glycol)s: PEG1000 (Janssen), PEG3400 (Aldrich) and dextranT70 from Sigma Chemical. The molecular weights are 1000,3400 and $70000 \mathrm{Da}$, respectively. The water used for the experiments was deionized water filtered through the Milli-Q-system of Millipore (resistivity $=18$ megaohm-cm). In Table 3 some physical properties of the various model components are given.

The molecular weight measurements have been performed in the laboratory of Pfennig and Gaube, Technische Hochschule Darmstadt. The experimental set-up and method used for these measurements were described by Connemann [44].

\subsection{Membranes}

The ultrafiltration experiments in the stirred cell were performed with asymmetric YM5, YM10 and YM30 membranes (Amicon) having a MW cut-off of 5000,10000 and $30000 \mathrm{Da}$, respectively. The structure of the YM10 membrane has been studied by Sheldon [45].

Table 3

Physical properties

\begin{tabular}{llll}
\hline & PEG1000 & PEG3400 & DextranT70 \\
\hline$M_{\mathrm{w}}\left[\mathrm{g} \mathrm{mol}^{-1}\right]$ & 1023 & 3600 & 98000 \\
$M_{\mathrm{w}} / M_{\mathrm{n}}$ & 1.13 & 1.18 & 1.9 \\
$\rho\left[\mathrm{kg} \mathrm{m}^{-3}\right]$ & 1200 & 1204 & 1600 \\
$V\left[\mathrm{~m}^{3} \mathrm{~mol}^{-1}\right]$ & $8.33 \times 10^{-4}$ & $2.82 \times 10^{-3}$ & $4.56 \times 10^{-2}$ \\
$d_{\mathrm{par}}[\mathrm{nm}]$ & $1.62^{\mathrm{a}} ; 1.95^{\mathrm{b}}$ & $3.10^{\mathrm{a}} ; 3.56^{\mathrm{b}}$ & $12.0^{\mathrm{c}}$ \\
\hline
\end{tabular}

a Tremblay [42].

b van der Linden [37].

${ }^{\mathrm{c}}$ Granath [43].

\subsection{Apparatus and methods}

\subsubsection{Stirred cell}

The flux and rejection measurements were carried out in a stirred batch cell (Amicon, type 2000A). The internal diameter of the cell is $14 \times 10^{-2} \mathrm{~m}$. The barlike stirrer has a diameter of $12 \times 10^{-2} \mathrm{~m}$. The effective area of the circular membrane is equal to $144 \times 10^{-4} \mathrm{~m}^{2}$ according to Amicon. The volume of the total permeate section between the bottom of the membrane and the liquid outlet has been determined with a displacement experiment and is equal to $27 \times 10^{-6} \mathrm{~m}^{3}$.

Since electrochemical measurements showed [16] that the mass transfer coefficient varies from the centre of the membrane towards the edge, similar cells were built with the possibility of collecting the permeate in two separate streams [16]. The membrane area connected with the inner permeate section was $72 \times 10^{-4} \mathrm{~m}^{2}$, the area connected with the outer section was $88 \times 10^{-4} \mathrm{~m}^{2}$. The experiments on the YM5 and YM10 membranes were carried out in a cell with one combined permeate collection, those on YM30 were performed with separate permeate collection.

Both cells were pressurized with nitrogen gas and the temperature was controlled by a thermostat. The temperature was maintained at $298 \mathrm{~K}$. The feed solution was preheated before being added to the cell. The permeate was collected in a time-based fraction collector to be able to take samples from the various fractions for concentration analysis. The amount of permeate per time was determined gravimetrically.

\subsubsection{Permeate flux and rejection measurements}

The feed solutions were prepared by dissolving weighed quantities of the components in water. Prior to filtration, samples were taken from the bulk solutions for concentration analysis. The bulk concentration was always $10 \mathrm{~kg} \mathrm{~m}^{-3}$, unless stated otherwise. After the working temperature was established the system was pressurized. The permeate was collected in fractions as a function of time.

To be sure that all liquid present in the permeate section prior to filtration was removed, permeate samples were taken from two subsequent fractions after $100 \mathrm{ml}$ of permeate was collected. If the pressure 
was varied during the experiment, the first $100 \mathrm{ml}$ of permeate collected after the pressure jump were not used for concentration analysis. In calculating the rejection of a sample the time lag for the permeate to reach the sample collector after passing through the membrane was taken into account. At the end of the experiment the system was depressurized and a retentate sample was taken.

The flux and rejection for the ternary system PEG/dextran/water system have been determined in two types of experiments:

1. By concentrating a PEG/dextran/solution at constant pressure. The concentrating experiments were performed at a constant pressure of $200 \mathrm{kPa}$.

2. By changing the pressure at constant PEG and dextran concentration. In the dead-end stirred cell the retentate was a little concentrated during filtration at constant pressure. In order to be able to measure the influence of pressure at the same concentration, the permeate was returned to the retentate after depressurizing the cell. Subsequently, a bulk sample was taken and a new pressure was set. The same procedure was followed for all pressures.

The initial bulk concentration was varied by adding the appropriate weight of dextran to a solution with an initial PEG concentration of $10 \mathrm{~kg} \mathrm{~m}^{-3}$. The PEG concentrations used for the calculation of the observed PEG rejection in the ternary system have been expressed as $\mathrm{kg} \mathrm{PEG} \mathrm{m}^{-3}$ (PEG + water), which excludes the amount of dextran present in the solution. Due to this definition the observed rejection is equal to zero, if all PEG permeates through the membrane.

\subsubsection{Concentration analysis}

The solute concentration in the samples was determined by HPLC (High Performance Liquid Chromatography). A Bio-SIL SEC 250 guard + column (Biorad) was used to separate PEG and dextran. Deionized water filtered through the Milli-Q-system was used as an eluent. The concentrations were determined by a refractive index detector (LKB, 2142). A standard solution with a known quantity PEG was alternately analyzed with the samples. The samples were measured in duplicate and the deviation between both measurements was $1-3 \%$.

\section{Results and discussion}

\subsection{Flux in ternary system}

The osmotic pressure of a binary dextran/water mixture is far lower than that of a PEG/water system of equal mass concentrations. Under filtration conditions, however, the osmotic pressure of dextran at the membrane surface is much higher due to a higher rejection and a lower diffusivity of dextran. The flux in the ternary PEG/dextran/water system (Fig. 2) is therefore mainly determined by the presence of dextran as was to be expected, since the flux for the binary dextran system is much lower than the one for the binary PEG system. The presence of PEG causes a small additional decrease in flux. The osmotic pressure in the ternary PEG/dextran/water system is considerably higher than in the binary dextran/water system (Fig. 3, the solid lines will be discussed in Section 4.3). Due to PEG-dextran interactions the ternary osmotic pressure is higher than the addition of the two binary osmotic pressures. Besides a rise in osmotic pressure the activities of both components are also increased by their mutual presence (Fig. 4(a) and (b)). This increase causes an increased back-diffusion of PEG and dextran to the bulk solution, which results in a lower concentration at the membrane surface for both components. The combination of both effects is a slight decrease in flux for the filtration conditions used for the experiments with PEG and dextran depicted in

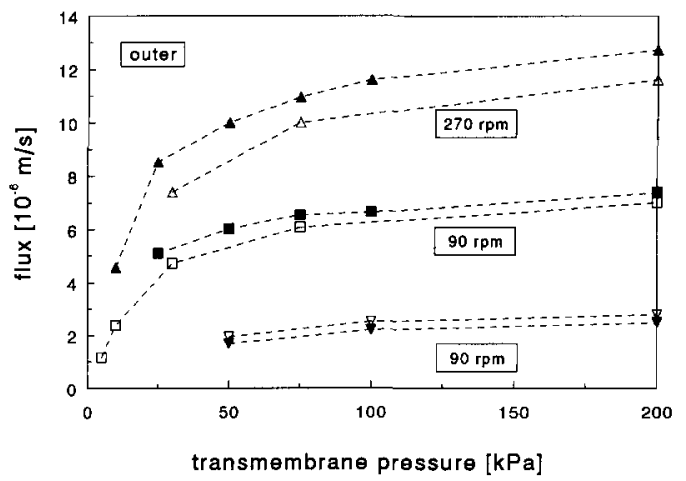

Fig. 2. The influence of PEG addition on the flux during dextranT70 filtration as a function of the transmembrane pressure for the outer section. YM30. $C_{\mathrm{dex}}=10 \mathrm{~kg} \mathrm{~m}^{-3}: n=90 \mathrm{rpm}$ ( $\left.\square\right)$ and $270 \mathrm{rpm}(\triangle) ; C_{\mathrm{dex}}=50 \mathrm{~kg} \mathrm{~m}^{-3}: n=90 \mathrm{rpm}(\nabla)$. Closed symbols: only dextran; open symbols: dextran $+\mathrm{PEG}, C_{\mathrm{PEG}}=$ $10 \mathrm{~kg} \mathrm{~m}^{-3}$. 


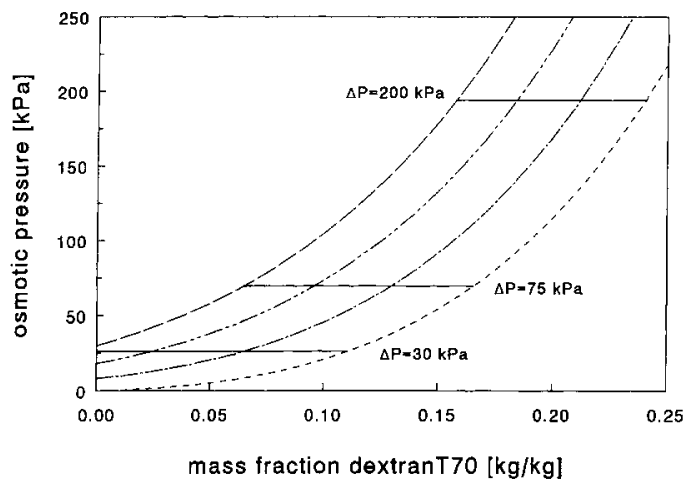

Fig. 3. Ternary osmotic pressure as a function of the mass fraction dextranT70 for various PEG3400 mass fractions. Mass fraction PEG: $0(--), 0.01(-\cdot-), 0.02(-\cdot-), 0.03 \mathrm{~kg} \mathrm{~kg}^{-1}(---)$.

(a)

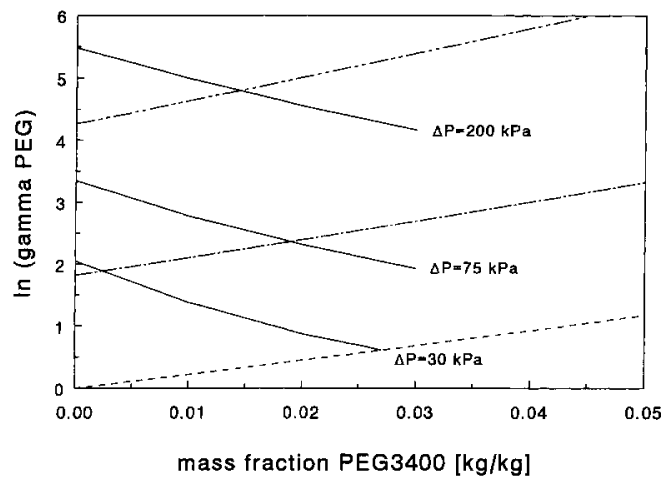

(b)

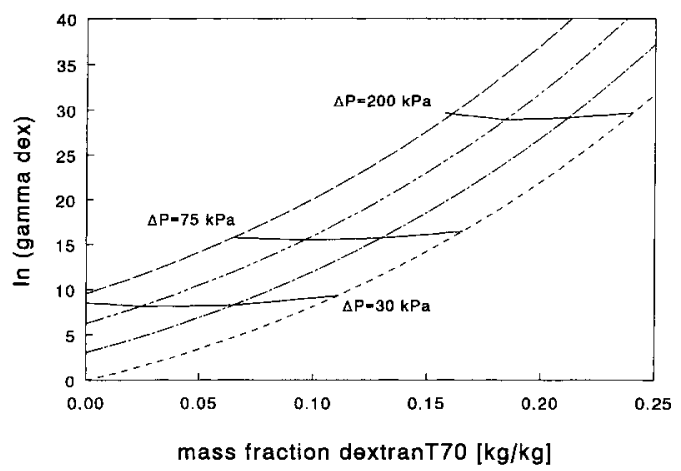

Fig. 4. (a) Ternary activity coefficient PEG3400 as a function of the mass fraction PEG for various dextranT70 mass fractions. Mass fraction dextran: $0(--), 0.1(-\cdot-), 0.2 \mathrm{~kg} \mathrm{~kg}^{-1}(-\cdot-)$. (b) Ternary activity coefficient dextranT70 as a function of the mass fraction dextran for various PEG3400 mass fractions. Mass fraction PEG: 0 (- - ), $0.01(-\cdot-), 0.02(-\cdot-), 0.03 \mathrm{~kg} \mathrm{~kg}^{-1}(---)$.

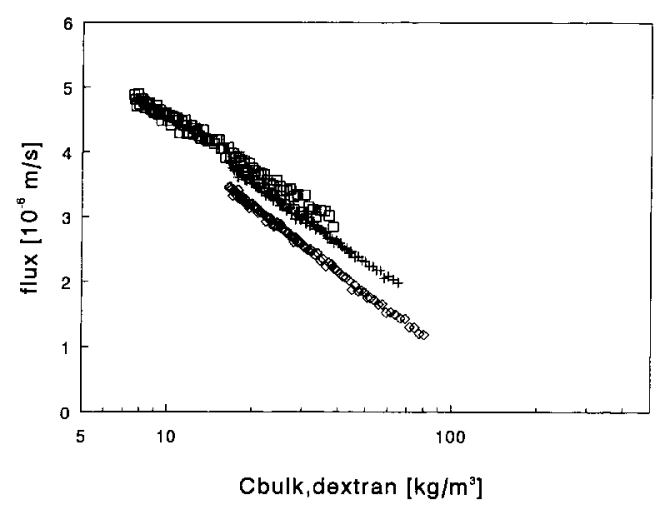

Fig. 5. Ternary flux during PEG3400 and dextranT70 filtration as a function of the dextran concentration for various PEG concentrations. YM5. $n=90 \mathrm{rpm}$. $C_{\mathrm{PEG}}: 0(\square), 2(+), 10 \mathrm{~kg} \mathrm{~m}^{-3}(\diamond)$.

Fig. 2, compared to the binary dextran/water experiment. In the figure only the data for the outer permeate section are presented; the results for the inner permeate section show a similar dependence of the flux with the pressure, only at lower absolute flux values.

The flux was also studied as a function of the dextran concentration. The experiments were performed by concentrating a PEG/dextran/water solution in a stirred cell with one permeate stream. In this case a YM5 membrane was used instead of a YM30 membrane as in Fig. 2. In Fig. 5 the flux is depicted as a function of the logarithm of the bulk concentration of dextran at three different PEG concentrations. The flux decreases by the addition of PEG: the higher the initial PEG concentration, the stronger the decrease. It can be concluded that the addition of PEG to the dextran solution does not change the often-observed linearity of the relationship between the flux and $\ln \left(C_{\mathrm{b}}\right)[28]$.

\subsection{Negative PEG rejections due to thermodynamic interactions with dextran.}

The rejection has been measured for dextranT70 with PEG1000 or PEG3400 and 2 different membranes. In Fig. 6 a typical result is given for the system PEG1000/dextranT70 on a YM10 membrane in a stirred cell with one combined permeate section. The observed rejection of PEG is depicted as a function of the flux at a constant pressure of $200 \mathrm{kPa}$. The decrease in flux is due to the rise of the dextran 


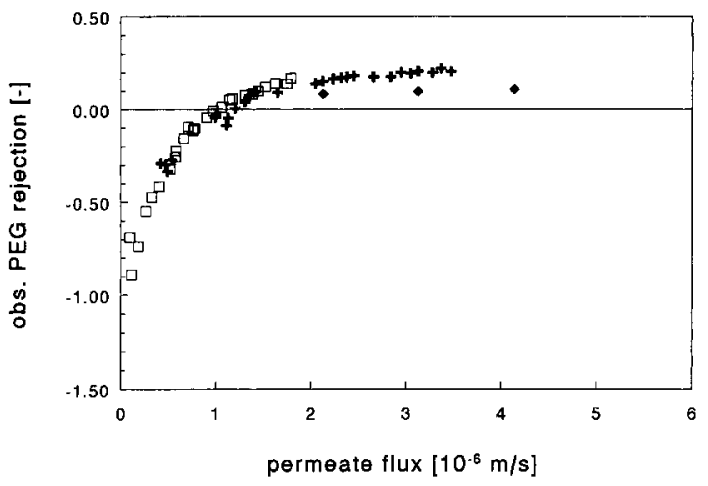

Fig. 6. PEG1000 rejection vs. permeate flux for various stirrer speeds in the presence of dextran T70. YM10. $\Delta P=200 \mathrm{kPa}$, $C_{\mathrm{PEG}} \approx 10 \mathrm{~kg} \mathrm{~m}^{-3}, C_{\mathrm{dex}}=20-288 \mathrm{~kg} \mathrm{~m}^{-3}, n=90(+), 120 \mathrm{rpm}$ (口). PEG1000 rejection without dextran: $\Delta P=20-40 \mathrm{kPa}$, $n=90 \mathrm{rpm}(\diamond)$.

concentration of the solution during the batch experiments. Starting from the highest flux to the lowest flux the dextran bulk concentration increases in a set of experiments from 7 to $250 \mathrm{~kg} \mathrm{~m}^{-3}$. The variation in PEG concentration (max. 10\%) is relatively small since the rejection has low values.

In the same figure also the rejection for PEG1000 without the presence of dextran is presented. To obtain comparable values for the permeate flux these rejections have been measured at lower transmembrane pressures. It is very important to compare the observed rejection at the same flux instead of at the same pressure, because the concentration polarization is determined by both the flux and the mass transfer coefficient and the actual rejection is a function of the flux (especially in the low flux region). Comparison of these results with the rejection in the ternary system shows that at high fluxes in the range of $2 \times 10^{-6}$ to $6 \times 10^{-6} \mathrm{~m} \mathrm{~s}^{-1}$ (which corresponds to low dextran concentrations) the presence of dextran causes the PEG rejection to increase from 0.1 to 0.2 . Decreasing the flux by concentration of the dextran in the PEG/dextran solution results in a decrease in PEG rejection. At fluxes below $1 \times 10^{-6} \mathrm{~m} \mathrm{~s}^{-1}$ the rejection becomes negative. Even values as low as -0.9 have been measured. It should be kept in mind that the rejection is based on concentrations in which only the amount of PEG and water are taken into account.

Rejection measurements for PEG1000 with a YM5 membrane also showed a strong decrease in PEG

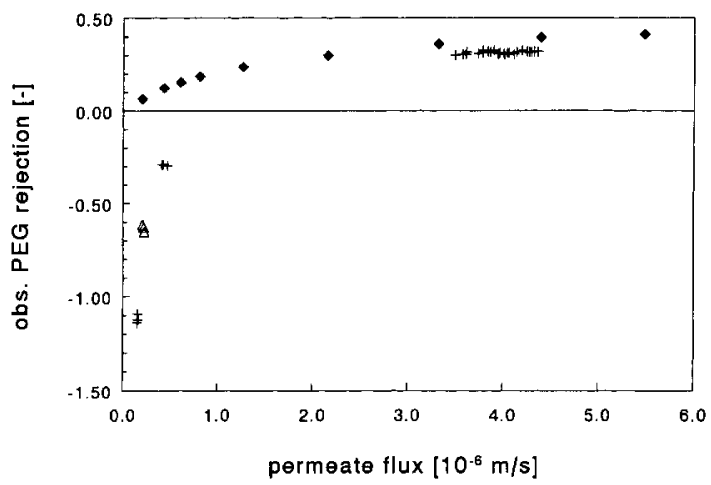

Fig. 7. PEG1000 rejection vs. permeate flux for various stirrer speeds in the presence of dextran T70. YM5. $\Delta P=200 \mathrm{kPa}$, $C_{\mathrm{PEG}}=10 \mathrm{~kg} \mathrm{~m}^{-3}, C_{\mathrm{dex}}=7-247 \mathrm{~kg} \mathrm{~m}^{-3}, \quad n=90 \mathrm{rpm} \quad(+)$, $270 \mathrm{rpm}(\triangle)$. PEG1000 rejection without dextran: $\Delta P=20$ $250 \mathrm{kPa}, n=90 \mathrm{rpm}(\bullet)$.

rejection in the presence of dextran compared with the rejection without dextran (Fig. 7). In this case a decrease in PEG rejection occurs over the entire flux range in contrast with the increase in the rejection, which has been observed at higher fluxes for YM10. In both Figs. 6 and 7 the variation in stirrer speed does not show a clear influence on the relationship between the rejection and the permeate flux.

The decrease in PEG rejection in the presence of dextran has also been found for PEG3400/dextranT70 on the YM5 membrane. An explanation for the negative rejection values is presented below.

Negative values for the PEG rejection imply, even more if they are calculated with concentrations based on kg PEG (volume PEG + water) ${ }^{-1}$, that the permeate concentration is larger than the bulk concentration. In other words, due to the presence of dextran the transport of PEG through the membrane is promoted to such extent that the permeate concentration reaches even higher values than the bulk concentration. According to the film model, the convective transport in the polarization layer is equal to $v \cdot C_{\mathrm{PEG}, \mathrm{b}}$ at the interface between bulk and film, which is in this case lower than the solute flux in the permeate $v \cdot C_{\mathrm{PEG}, \mathrm{p}}$. Besides convective transport, diffusion must occur in the direction of the membrane in order to explain the high PEG concentrations in the permeate. The diffusional transport of PEG is thus opposite in direction compared to the normally encountered situation. This means that the presence of dextran should cause an 
extra driving force for PEG transport through the membrane besides the pressure gradient.

The presence of dextran at the retentate side of the membrane strongly increases the activity coefficient of PEG. Due to the high rejection of dextran the activity coefficient of PEG in the permeate is close to one. Therefore, a large difference in PEG activity exists between both sides of the membrane which causes considerable diffusion flux through the membrane. Especially at low fluxes where diffusion in the membrane is predominant the influence on the rejection is the most pronounced. Negative rejections can only be achieved if the PEG activity in the bulk solution is higher than in the permeate solution, in spite of the higher PEG concentration in the permeate. The higher the dextran concentrations, the stronger the increase of the diffusive flux of PEG through the membrane. In this experiment high dextran concentrations and low fluxes go together which reinforces the decrease in PEG rejection.

To estimate whether the increase in the PEG activity coefficient in the presence of dextran is indeed sufficient to cause the augmented PEG transport in the polarization layer and the membrane a simplified calculation of the activity profiles has been performed. The conditions used for the calculation are bulk concentrations of $10 \mathrm{~kg} \mathrm{~m}^{-3}$ PEG1000 and $173 \mathrm{~kg} \mathrm{~m}^{-3}$ dextran, a flux of $4.8 \times 10^{-7} \mathrm{~m} \mathrm{~s}^{-1}$ and an observed rejection of -0.34 . These values for the observed rejection and flux have been measured experimentally for these bulk concentrations on the YM10 membrane.

Since no data on Stefan-Maxwell diffusion coefficients for PEG and dextran are available in the literature, a more simplified description is applied to obtain an indication of the activity gradient over the membrane. As a first estimate it is assumed that the concentration profile of dextran is hardly affected by the low concentrations of PEG and the concentration profile has been calculated from binary dextran/ water measurements. From the dextran profile in the polarization layer (calculated with the film model: $\left.C=C_{\mathrm{p}}+\left(C_{\mathrm{b}}-C_{\mathrm{p}}\right) \exp \left(v / k_{\mathrm{m}}\right)\right)$ the activity coefficients for PEG can be found. The diffusion coefficient of PEG has been taken constant and equal to the bulk diffusivity without correction for the presence of dextran. The results of the calculation, which are depicted in Fig. 8, show that the activity of PEG1000 is indeed higher in the bulk and in the

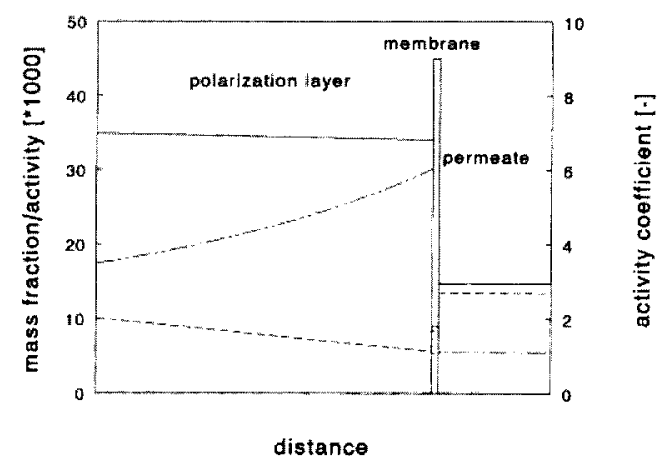

Fig. 8. Mass fraction (--), activity (- $\longrightarrow$ ) profiles: left hand scale and activity coefficient $(-\cdot-)$ profiles: right hand scale of PEG1000 in polarization layer and membrane at $v=4.8 \times 10^{-7} \mathrm{~m} / \mathrm{s}$ and $R_{0}=-0.34 . C_{\mathrm{dex}}=173 \mathrm{~kg} \mathrm{~m}^{-3} . \mathrm{YM} 10$. $n=90 \mathrm{rpm} . \Delta P=200 \mathrm{kPa}$.

polarization layer than in the permeate, which means an additional driving force due to a difference in thermodynamic activity between both sides of the membrane. The activity profile in the polarization layer has a negative gradient which indicates a positive diffusion in the direction of the membrane. Since the activity coefficient of PEG increases in the direction towards the membrane due to the higher dextran concentrations near the membrane surface, the gradient in mass fraction is even more negative than that for the PEG activity. In this example the loss in driving force in the polarization layer is small compared to that in the membrane.

\subsection{Increase of $P E G$ rejection in the presence of dextran}

In the experiments discussed above the flux was varied by concentrating the PEG/dextran/water solution. The rejection in the ternary system has also been studied at constant bulk concentrations of PEG6000 and dextranT70 at various pressures. The solutions were filtered through a YM30 membrane which is more open than the membranes used for the concentration experiments. Therefore, higher fluxes could be reached during filtration. The bulk concentrations of dextran in these experiments were $10 \mathrm{~kg} \mathrm{~m}^{-3}$ and $50 \mathrm{~kg} \mathrm{~m}^{-3}$. These values were relatively low compared to the highest concentrations reached in the concentrating experiments. In this way the influence of PEG-dextran interactions could also be studied in 
(a)

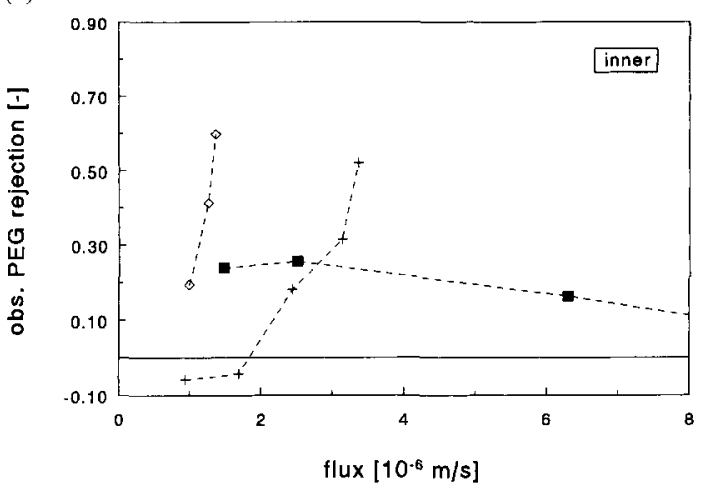

(b)

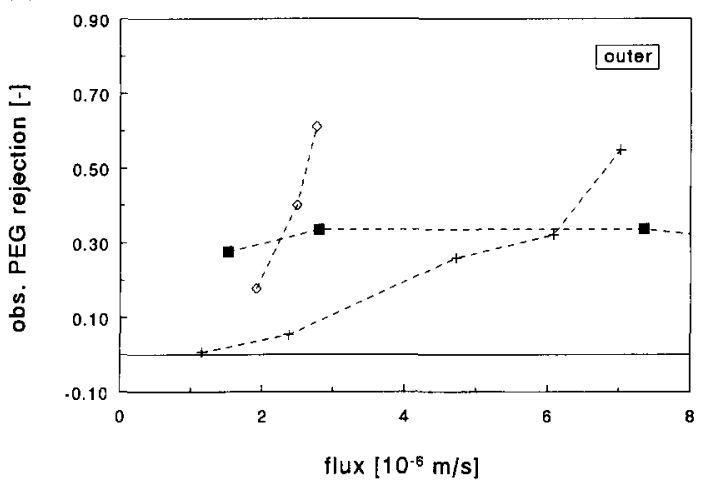

Fig. 9. (a) Observed PEG3400 rejection as a function of the flux in the presence of dextran $\mathrm{T} 70$ for the inner section. YM30. $n=90 \mathrm{rpm} . C_{\mathrm{PEG}}=10 \mathrm{~kg} \mathrm{~m}^{-3} \cdot C_{\mathrm{dex}}=10 \mathrm{~kg} \mathrm{~m}^{-3}(+): \Delta P=5-$ $200 \mathrm{kPa}$ and $C_{\mathrm{dex}}=50 \mathrm{~kg} \mathrm{~m}^{-3}(\diamond): \Delta P=30-200 \mathrm{kPa}$. PEG1000 rejection without dextran ( $\square): \Delta P=5,10$ and $25 \mathrm{kPa}$. (b) Idem for the outer section.

the high flux region. In Fig. 9(a) and (b) the PEG rejection is presented as a function of the flux for two dextran concentrations in the inner and outer section, respectively. As a comparison the PEG rejection is also given without dextran present.

Remarkable differences between the PEG rejection in the presence and absence of dextran have been found. The observed PEG rejection in the presence of dextran shows a strong increase with the flux, whereas the PEG rejection in the binary system remains equal or even decreases. The PEG rejections for the two different dextran concentrations do not appear to coincide on one curve as a function of flux as is the case of the concentration experiments at constant pressure. Moreover, the PEG rejections in the inner and outer section are very similar at each pressure for each of the two bulk concentrations, although the flux differs considerably between the two sections. This indicates that the observed PEG rejection is more related to the pressure difference than to the filtration flux. Another feature is the increase of the PEG rejection for the highest pressures compared to the PEG rejection for the binary system at the same flux. The influence of both thermodynamic effects and friction effects on the rejection behaviour in the ternary system is discussed below. The interaction can take place in the polarization layer, at the membrane surface and in the membrane pores.

\subsubsection{Thermodynamic effects}

As we have seen for the concentrating experiments dextran can strongly influence the thermodynamic activity of PEG, especially at high dextran concentrations. Therefore it is interesting to know the value of the dextran concentration at the membrane surface for the various pressures applied. In the ternary system it is not possible to derive one value of the dextran concentration at the membrane surface from the osmotic pressure, as can be done for the binary dextran/ water system. However, if the experimental osmotic pressure is derived from the osmotic pressure model:

$v=\frac{\Delta P-\sigma \Delta \Pi}{\eta_{\mathrm{p}} R_{\mathrm{m}}}$

using experimental values for $v, \eta_{\mathrm{p}}$ and $R_{\mathrm{m}}$ and as a first assumption $\sigma=1$, a range of combinations of PEG and dextran concentrations can be determined by means of the UNIQUAC model which all yield that value for the osmotic pressure. The osmotic pressure in the permeate has been neglected compared to the osmotic pressure at the membrane surface. These combinations of PEG and dextran concentrations can be read from Fig. 3 for the transmembrane pressures of 30,75 and $200 \mathrm{kPa}$ for a bulk concentration of $10 \mathrm{~kg} \mathrm{~m}^{-3}$ dextran and $10 \mathrm{~kg} \mathrm{~m}^{-3}$ PEG in the inner permeate section. From Fig. 3 the concentration at the membrane surface lines is projected into Fig. 4(a) and (b) as the solid lines to be able to obtain an indication of the corresponding PEG and dextran activities.

The values of the activity coefficients of PEG at the membrane surface are considerably higher at $200 \mathrm{kPa}$, $\gamma_{\mathrm{PEG}}^{\mathrm{wt}}=65-240$, than at $30 \mathrm{kPa}, \gamma_{\mathrm{PEG}}^{\mathrm{wt}}=1.8-7.8$, as a result of the higher dextran concentrations at the 
membrane surface (Fig. 4(a)). According to Eqs. (5)(9) this implies an extra driving force for back diffusion in the polarization layer as well as for diffusion through the membrane $\left(c_{j} \cdot \ln \left(\gamma_{\mathrm{PEG}}^{\mathrm{wt}}\right)\right.$ at $200 \mathrm{kPa}$ is larger than at $30 \mathrm{kPa}$ ). This will result in a lower PEG concentration at the membrane interface if $\Delta P=200 \mathrm{kPa}$. The resulting lower PEG concentration in the polarization layer will decrease the convective transport - first RH term in Eq. (6) - towards the membrane, thus leading to a further decrease in the PEG concentration at the membrane interface. The interface concentration may even get lower than the bulk concentration and still provide back diffusion to the bulk due to the strong gradient of $\ln \left(\gamma_{\mathrm{PEG}}^{\mathrm{Wt}}\right)$ in the polarization layer as a result of the increasing dextran concentration from bulk to membrane interface. The further reduction of the $\mathrm{PEG}$ interface concentration at $\Delta P=200 \mathrm{kPa}$ will result in a reduced transport of PEG through the membrane - and thus in a higher retention of PEG - compared to the situation with a lower $\Delta P$ or without dextran present.

Another possibility could be that due to the thermodynamic interactions demixing of the PEG/dextran/ water system in a dextran-rich and a PEG-rich phase occurs at high concentrations at the membrane surfaces. However, the dextran-rich phase would have almost the same composition as the demixing solution and only a small amount of PEG-rich phase would be formed. Therefore, permeation of the dextran-rich phase would not alter the picture. The permeation of a PEG-rich phase would increase the permeate concentration which is in contradiction with the experimentally observed increase in rejection.

\subsubsection{Friction effects}

Besides effects due to the change in thermodynamic activity the PEG transport can also be influenced by friction between dextran and PEG. The increase in dextran concentration with increasing pressure could cause a stronger friction between PEG and dextran in the polarization layer during the transport towards the membrane. This may lead to a higher PEG rejection. The fact that at high fluxes the PEG rejection for the YM10 membrane (Fig. 6) also increases in the presence of dextran indicates that the difference in dextran concentration in the bulk and at the membrane surface is important. For the YM5 membrane, where the dextran concentration at the membrane surface is

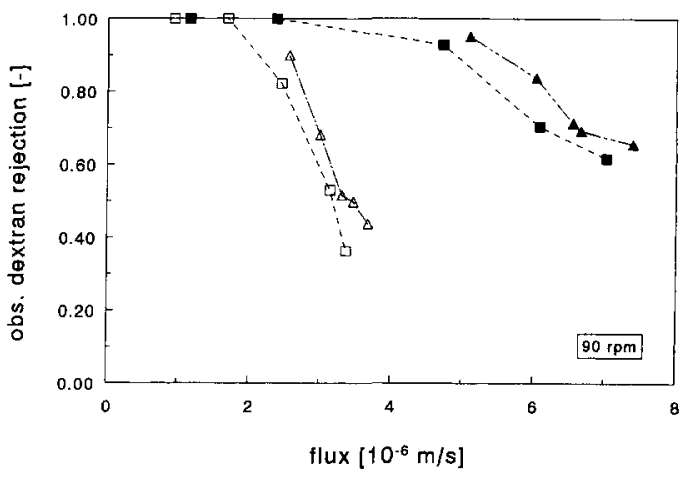

Fig. 10. Observed dextranT70 rejection as a function of the flux in the presence of PEG3400 for $90 \mathrm{rpm}$. YM30. $C_{\mathrm{PEG}}=10 \mathrm{~kg} \mathrm{~m}^{-3}$. $C_{\text {dex }}=10 \mathrm{~kg} \mathrm{~m}^{-3}(\square): \Delta P=5-200 \mathrm{kPa}$. DextranT70 rejection without PEG3400 $(\triangle): \Delta P=25-200 \mathrm{kPa}$. Open symbols: inner section; closed symbols: outer section.

lower due to the lower permeate flux, such an increase was not found.

The increased PEG rejection in the presence of dextran at higher pressures could be the result of hindrance of the passage of a PEG molecule through the pore. The observed dextran rejections increase with increasing pressure, leading to a higher dextran concentration in the pore (see Fig. 10). However, dextran rejection for $50 \mathrm{~kg} / \mathrm{m}^{3}$ dextran varies only between 0.81 and 0.71 for 50 to $200 \mathrm{kPa}$, whereas the PEG rejection shows a considerable increase. Also, at a given pressure the dextran rejections differ for the inner and outer sections, whereas the PEG rejections are nearly equal.

From the above discussed explanations for the increase of PEG rejection in the presence of dextran, the increase in PEG activity coefficient and the friction in the polarization layer due to the presence of dextran are in accordance with the effect of the pressure on the PEG rejection. Demixing and hindrance in the pore cannot explain the observed rejections.

\subsection{Dextran rejection in the presence of PEG}

The addition of PEG to the dextran solution caused a small decrease in dextran rejection compared to the dextran rejection in the binary system at the same flux (see Fig. 10). This can be understood as follows. In the presence of PEG the dextran concentration at the 
membrane surface is lower at the same flux because the ternary osmotic pressure is higher than the binary osmotic pressure (see Fig. 3). Without the presence of PEG a lowering of the dextran concentration would imply a strong decrease in dextran activity which would result in an increase in the observed dextran rejection. This lower concentration at the membrane surface is compensated by the increase in activity coefficient of dextran in the presence of PEG. According to the experimental rejection these counteracting effects result in a slight increase in permeate concentration and a minor decrease in the dextran rejection. In Fig. 4(b) it can be seen for the lines at equal osmotic pressure that despite the presence of $\mathrm{PEG}, \ln \left(\gamma_{\mathrm{dex}}^{\mathrm{wt}}\right)$ slightly decreases in the presence of PEG due to the lower dextran concentration. Given the uncertainties in the thermodynamic model (originating from the demixing data) one may assume that a small rise in dextran activity coefficient compared to the activity coefficient in the absence of PEG might be possible.

\section{Conclusions}

Solute interaction can strongly influence the rejection of the components during ultrafiltration. Rejection measurements on YM5 and YM10 membranes show a decrease in PEG rejection if dextran is added to the PEG solution. This effect can be qualitatively explained by the influence of dextran on the thermodynamic activity of PEG. The strongest decrease in PEG rejection has been found for low fluxes where diffusion is predominant and the dextran bulk concentration is the highest. Under these conditions the rejection of PEG can even become strongly negative which means that the concentration of PEG in the permeate is higher than in the bulk solution. Due to the additional driving force of the activity gradient, more PEG permeates through the membrane than the amount of PEG transported towards the membrane by pressure-induced convective transport.

At high flux conditions for a low resistance membrane PEG rejection shows an opposite behaviour: a considerable increase in rejection which might be the result of the much higher activity coefficient of PEG at the membrane surface compared to the one in the bulk solution due to the strong concentration polarization of dextran. The friction between PEG and dextran molecules due to the strong concentration polarization of the dextran molecules may also contribute to the increase in PEG rejection.

The results in this paper clearly indicate that multicomponent phenomena, especially thermodynamic interactions, can have a strong impact on the observed rejection and are certainly worth being considered in multicomponent systems. Increased transport of small components by addition of large thermodynamically interactive components is a phenomenon which might be used advantageously for the simultaneous concentration and purification of solutions.

\section{List of symbols}

$a_{j} \quad$ thermodynamic activity component $j$ at reference $T$ and $P[-]$

$A_{j k} \quad$ interaction parameter between components $j$ and $k[\mathrm{~K}]$

$B_{0} \quad$ permeability $\left[\mathrm{m}^{2}\right]$

$c_{\mathrm{t}} \quad$ total molar concentration $\left[\mathrm{mol} \mathrm{m}^{-3}\right]$

$C \quad$ solute/particle concentration $\left[\mathrm{kg} \mathrm{m}^{-3}\right]$

$d_{\text {par }} \quad$ particle diameter [m]

$D \quad$ Fick diffusion coefficient in bulk solution $\left[\mathrm{m}^{2} \mathrm{~s}^{-1}\right]$

$D_{j, k}^{\mathrm{sm}} \quad$ Stefan-Maxwell diffusion coefficient of $j-k$ pair $\left[\mathrm{m}^{2} \mathrm{~s}^{-1}\right]$

$D_{j, m} \quad$ Stefan-Maxwell 'membrane' diffusion coefficient component $j\left[\mathrm{~m}^{2} \mathrm{~s}^{-1}\right]$

$K \quad$ Equilibrium coefficient [-]

$K_{\mathrm{c}} \quad$ hindrance factor for convection [-]

$K_{d} \quad$ hindrance factor for diffusion [-]

$k_{\mathrm{m}}$

$m_{\mathrm{PEG}}$

$M_{j}$

$M_{\mathrm{n}}$

$M_{\mathrm{w}}$

$N_{j} \quad$ molar flux with respect to stationary coordinates $\left[\mathrm{mol} \mathrm{m}^{-2} \mathrm{~s}^{-1}\right.$ ]

$n_{\text {comp }} \quad$ number of components

$P \quad$ pressure $[\mathrm{Pa}]$

$\Delta P \quad$ transmembrane pressure $[\mathrm{Pa}]$

$q_{j}^{\prime} \quad$ surface area parameter $\left[\mathrm{mol} \mathrm{g}^{-1}\right]$

$r_{j}^{\prime} \quad$ volume parameter $\left[\mathrm{mol} \mathrm{g}^{-1}\right]$

$R \quad$ molar gas constant $\left[\mathrm{J} \mathrm{mol}^{-1} \mathrm{~K}^{-1}\right]$ 
$T \quad$ temperature $[\mathrm{K}]$

$u_{j k} \quad$ interaction energy $\left[\mathrm{J} \mathrm{mol}^{-1}\right]$

$v \quad$ solution velocity, flux $\left[\mathrm{m} \mathrm{s}^{-1}\right]$

$V_{j} \quad$ partial molar volume component $j$ $\left[\mathrm{m}^{3} \mathrm{~mol}^{-1}\right]$

$w_{j} \quad$ mass fraction $\left[\mathrm{kg} \mathrm{kg}^{-1}\right]$

$x_{j} \quad$ mole fraction of component $j$

$\left[\mathrm{mol} \mathrm{mol}{ }^{-1}\right.$ ]

$z \quad$ coordination number in UNIQUAC and LQCA [-]

$z \quad$ coordinate perpendicular to the membrane surface $[\mathrm{m}]$

\subsection{Greek}

$\gamma_{j} \quad$ activity coefficient component $j$ based on mole fractions $\left[\mathrm{mol} \mathrm{mol}^{-1}\right]$

$\gamma^{\text {wt }} \quad$ activity coefficient component $j$ based on mass fractions $\left[\mathrm{kg} \mathrm{kg}^{-1}\right]$

$\varepsilon \quad$ porosity $\left[\mathrm{m}^{3} \mathrm{~m}^{-3}\right]$

$\eta \quad$ viscosity of the solution [Pa s]

$\theta_{j}^{\prime} \quad$ surface area fraction component $j$ $\left[\mathrm{m}^{2} \mathrm{~m}^{-2}\right]$

$\mu_{j} \quad$ chemical potential component $j\left[\mathrm{~J} \mathrm{~mol}^{-1}\right]$

$\Pi \quad$ osmotic pressure [Pa]

$\rho_{j} \quad$ mass concentration component $j\left[\mathrm{~kg} \mathrm{~m}^{-3}\right]$

$\rho_{\text {tot }} \quad$ total density $\left[\mathrm{kg} \mathrm{m}^{-3}\right]$

$\sigma \quad$ osmotic reflection coefficient $[-]$

$\tau \quad$ tortuosity $[-]$

$\phi_{j}{ }^{\prime} \quad$ volume fraction in UNIQUAC $\left[\mathrm{m}^{3} \mathrm{~m}^{-3}\right]$

\subsection{Subscript}

1,2 solute 1 , solute 2

3 solvent

b bulk

dex dextran

PEG poly(ethylene glycol)

$\mathrm{p}$ permeate

s solute

t total

T,P constant temperature and pressure

w water

\subsection{Superscript}

" heterogenous description, property concerns solution inside the pore

\section{Acknowledgements}

Acknowledgements are made to IOP-membranes, Technology foundation, Akzo Nobel, Gist-Brocades, Royal Dutch/Shell, Stork Friesland and Unilever for their financial support. We highly appreciate the contributions of Dr. Nies (Eindhoven University of Technology) and Dr. Pfennig (University of Darmstadt) in the modelling of the thermodynamics. Defesche and Kaethoven are thanked for their contributions to this work.

\section{References}

[1] H. Strathmann, Untersuchungen zur Konzentrationsüberhöhung bei der Membranfiltration. II. Konzentrationsüberhöhung bei der Filtration von makromolekularen Lösungen, Chemie Ing.-Techn., 45 (1973) 825.

[2] S. Nakao, S. Yumoto and S. Kimura, Analysis of rejection characteristics of macromolecular gel layer for low molecular weight solute in ultrafiltration, J. Chem. Eng. Jpn., 15 (1982) 463.

[3] S. Kimura, T. Ohtani and A. Watanabe, Nature of dynamically formed ultrafiltration membranes, ACS Symp. Ser., 281 (1985) 35.

[4] P.J.A.M. Kerkhof and G.H. Schoutens, Membrane processing of industrial enzymes, in: S. Bruin (ed.), Preconcentration and drying of food materials, Elsevier, Amsterdam, 1988, p.87.

[5] S. Mochizuki and A.L. Zydney, Effect of protein adsorption on the transport characteristics of asymmetric ultrafiltration membranes, Biotechnol. Prog., 8 (1992) 553.

[6] S. Mochizuki and A.L. Zydney, Sieving characteristics of albumin deposits formed during microfiltration, J. Colloid Interface Sci., 158 (1993) 136.

[7] M. Meireles, P. Aimar and V. Sanchez, Effects of protein fouling on the apparent pore size distribution of sieving membranes, J. Membrane Sci., 56 (1991) 13.

[8] C.W. van Oers, M.A.G. Vorstman and P.J.A.M. Kerkhof, Solute rejection in the presence of a deposited layer during ultrafiltration, J. Membrane Sci., 107 (1995) 173.

[9] N. Papamichael and M.R. Kula, A hydrodynamic study of the retention of polyethylene glycols by cellulose acetate membranes in the absence and presence of proteins, J. Membrane Sci., 30 (1987) 259.

[10] T.F. Busby and K.C. Ingham, Separation of macromolecules by ultrafiltration: Removal of poly(ethylene glycol) from human albumin, J. Biochem. Biophys. Methods, 2 (1980) 191.

[11] C.M. Tam and A.Y. Tremblay, Membrane pore characterization-comparison between single and multicomponent solute probe techniques, J. Membrane Sci., 57 (1991) 271.

[12] A.G. Bozzano and C.E. Glatz, Separation of proteins from polyelectrolytes by ultrafiltration, J. Membrane Sci., 55 (1991) 199. 
[13] J.A. Wesselingh, P. Vonk, Ultrafiltration of a large electrolyte, 99, 1995, 21.

[14] W.R. Bowen and H. Mukhtar, Characterisation and prediction of separation performance of nanofiltration membranes, $J$. Membrane Sci., 112 (1996) 263.

[15] C.W. van Oers, Ph.D. Thesis, Eindhoven University of Technology, Eindhoven, The Netherlands, 1994.

[16] C.W. van Oers, W.G.H.M. Muijselaar, M.A.G. Vorstman and P.J.A.M. Kerkhof, Unsteady-state flux behaviour in relation to the presence of a gel layer, J. Membrane Sci., 73 (1992) 231.

[17] C.H. Kang and S.I. Sandler, A thermodynamic model for twophase aqueous polymer systems, Biotechnol. Bioeng., 32 (1988) 1158.

[18] E.N. Lightfoot, Transport Phenomena and Living Systems, (Wiley and Sons, New York, 1974).

[19] E.A. Mason and L.A. Viehland, Statistical-mechanical theory of membrane transport for multicomponent systems: Passive transport through open membranes, J. Chem. Phys., 68 (1978) 3562 .

[20] R. Krishna, A unified theory of separation processes based on irreversible thermodynamics, Chem. Eng. Comm., 33 (1987a) 59.

[21] R. Krishna, A simplified procedure for the solution of the Dusty Gas Model equations for steady-state transport in nonreacting systems, Chem. Engng. J., 35 (1987) 75.

[22] R. Jackson, Transport in Porous Catalysts, (Elsevier, Amsterdam, 1977).

[23] B.C. Robertson and A.L. Zydney, Stefan-Maxwell analysis of protein transport in porous membranes, Sep. Sci. Technol., 23 (1988) 1799.

[24] P.J.A.M. Kerkhof, A modified Maxwell-Stefan model for transport through inert membranes: The binary friction model. To be published in Chem. Eng. J.

[25] J.D. Ferry, Statistical evaluation of sieve constants in ultrafiltration, J. General Physiology, 20 (1936) 95.

[26] P. Vonk, Diffusion of large molecules in porous structures, thesis, University of Groningen, The Netherlands (1994).

[27] E.A. Mason and L.F. del Castillo, The role of viscous flow in theories of membrane transport, J. Membrane Sci, 23 (1985) 199.

[28] J.G. Wijmans, S. Nakao, J.W.A. van den Berg, F.R. Toelstra and C.A. Smolders, Hydrodynamic resistance of concentration polarization boundary layers in ultrafiltration, $\mathbf{J}$. Membrane Sci., 22 (1985) 117.
[29] P. Erikson, Reverse Osmosis, Ultrafiltration and mass transfer in turbulent duct flow, Ph.D. thesis, 1980, Lund institute of Technology, Lund, Sweden.

[30] Ch. Rosén and Ch. Trägårdh, Computer simulations of mass transfer in the concentration boundary layer over ultrafiltration membranes, J. Membrane Sci., 85 (1993) 139.

[31] A.L. Zydney, Concentration effects on membrane sieving: Development of a stagnant film model incorporating the effects of solute-solute interactions, J. Membrane Sci., 68 (1992) 183.

[32] J.L. Anderson and J.A. Quinn, Restricted transport in small pores. A model for steric exclusion and hindered particle motion, Biophys. J., 14 (1974) 130.

[33] W.M. Deen, Hindered transport of large molecules in liquidfilled pores, 33 (1987) 1409.

[34] D.S. Abrams and J.M. Prausnitz, AIChE J., 21 (1975) 116.

[35] C.H. Kang and S.I. Sandler, Effects of polydispersivity on the phase behavior of aqueous two-phase polymer systems, Macromolecules, 21 (1988) 3088.

[36] A. Fredenslund, J. Gmehling and P. Rasmussen, Vapor-liquid equilibria using UNIFAC, (Elsevier: Amsterdam, 1977).

[37] J.M. van der Linden, De diffusie van polyethyleenglycol in water, Ph.D. thesis, Rijksuniversiteit Leiden, 1973.

[38] R.S. King, H.W. Blanch and J.M. Prausnitz, Molecular thermodynamics of aqueous two-phase systems for bioseparations, AIChE J., 34 (1988) 1585.

[39] W.G. Madden, J. Chem. Phys., 92 (1990) 2055.

[40] C.H. Kang and S.I. Sandler, Phase behavior of aqueous twopolymer systems, Fluid Phase Equilib., 38 (1987) 245.

[41] E.A. Guggenheim, Mixtures (Clarendon Press, Oxford, 1952).

[42] A.Y. Tremblay, Finely porous models and radially averaged friction factors, J. Appl. Polym. Sci., 35 (1992) 159.

[43] K.A. Granath and B.E. Kvist, Molecular weight distribution analysis by gel chromatography on Sephadex, J. Chromatogr., 28 (1967) 69.

[44] M. Connemann, Untersuchungen zur Thermodynamik wässriger zweiphasiger Polymersysteme und Bestimmung von Proteinverteilungskoeffizienten in diesen Extraktionssystemen, Fortschr.-Ber. VDI Reihe 3, nr. 293, VDI-verlag, Düsseldorf, 1992.

[45] J.M. Sheldon, The fine structure of ultrafiltration membranes I. Clean membranes, J. Membrane Sci., 62 (1991) 75. 